\title{
O NOVO IMPERIALISMO E O NEOLIBERALISMO NAS POLÍTICAS DAS INSTITUIÇÕES DE JUSTIÇA NA AMÉRICA LATINA: Uma Análise a Partir da Reforma do Poder Judiciário Brasileiro e da Busca pela Consolidação do Estado Democrático de Direito
}

http://dx.doi.org/10.21527/2176-6622.2020.53.128-140

Recebido em: 23/7/2019

Aceito em: 20/1/2020

Edith Maria Barbosa Ramos

Pós-Doutora em Direito Sanitário pela Fundação Oswaldo Cruz (Fiocruz/Brasília/DF). Doutora em Políticas Públicas pela Universidade Federal do Maranhão. Mestra em Direito pela Universidade Federal de Minas Gerais. Graduada em Direito pela Universidade Federal do Maranhão. Professora do Departamento de Direito da Universidade Federal do Maranhão. Professora do Mestrado em Direito e Instituições do Sistema de Justiça da Universidade Federal do Maranhão. Coordenadora do Núcleo de Estudos em Direito Sanitário (Nedisa/UFMA). Professora e Pesquisadora da Universidade Ceuma. Bolsista do Bepp/Fapema (bolsa de Estímulo à Produtividade em Pesquisa - Edital no 007/2018 - Produtividade). Membro Convidado da Rede Ibero-Americana de Direito Sanitário e da Associação Lusófona de Direito da Saúde (Aldis). Presidente da Comissão de Bioética e Biodireito do Conselho Seccional da OAB/MA. Tem experiência na área de Direito, com ênfase em Sociologia do Direito, Direito Constitucional e Direito Administrativo, atuando principalmente nos seguintes temas: direito sanitário, propriedade intelectual, inovação e políticas públicas. http://lattes.cnpq.br/7085054421011701. https://orcid.org/0000-0001-6064-1879. edithramosadv@yahoo.com.br

\section{RESUMO}

Edson Barbosa de Miranda Netto

Mestre em Direito e Instituições do Sistema de Justiça pela Universidade Federal do Maranhão (PPGDIR/UFMA). Especialista em Direito Constitucional pela Universidade Anhanguera-Uniderp. Graduado em Direito pela Universidade Federal do Maranhão (UFMA). Pesquisador do Núcleo de Estudos em Municipalidades e Direito (Nemud - Universidade Ceuma). Professor da Universidade Ceuma. Professor-substituto da Universidade Estadual do Maranhão (Uema). Advogado pela OAB/MA. http://lattes.cnpq.br/7945424930359466. https://orcid. org/0000-0002-2981-5735. nettoedson@hotmail.com

O presente artigo objetiva analisar as influências das políticas neoliberais e do novo imperialismo norte-americano na reforma do Poder Judiciário brasileiro promovida por meio da EC n. 45/04. Foram analisadas as reformas políticas e econômicas patrocinadas nos países da América Latina pelos EUA e por organismos financeiros internacionais, sobretudo nas décadas de 80 e 90 . Adotou-se a metodologia da revisão sistemática, configurada a partir de estudo bibliográfico e documental. Concluiu-se que, apesar de haver elementos positivos nesse processo de reforma do sistema de Justiça brasileiro, como a busca por maior eficiência e celeridade nos processos, a reforma do sistema judicial brasileiro de 2004 mostrou-se limitada, com a construção insuficiente de mecanismos capazes de efetivamente melhorar a prestação jurisdicional, a exemplo dos meios alternativos de resolução de demandas.

Palavras-chave: Novo imperialismo. Neoliberalismo. América Latina. Reforma do poder judiciário. Emenda constitucional n. $45 / 04$.

NEW IMPERIALISM AND NEOLIBERALISM IN JUSTICE INSTITUTIONS POLICIES OF LATIN AMERICAN: AN ANALYSIS OF THE BRAZILIAN JUDICIAL BRANCH REFORM AND THE SEARCH FOR THE CONSOLIDATION OF THE DEMOCRATIC RULE OF LAW

\section{ABSTRACT}

The present article aims to analyze the influences of neoliberal policies and the new US imperialism on the Reform of the Brazilian Judiciary Power promoted through the Constitutional Amendment n. 45/04. In order to reach this goal, the political and economic reforms sponsored in the Latin American countries by the US and international financial institutions will be analyzed, especially in the 1980s and 1990s. With regard to the methodology used, this article adopted the systematic review. It was concluded that, although there are positive elements in neoliberal influences, such as the search for greater efficiency and faster decisions in the Judiciary, the reform of the Brazilian judicial system in 2004 was limited, and the construction of mechanisms capable of effectively improving the jurisdictional assistance was insufficient, such as the stimulation of alternative means of conflict resolution.

Keywords: New imperialism. Neoliberalism. Latin America. Judicial system reform. Constitutional amendment $\mathrm{n}$. $45 / 04$.

\section{SUMÁRIO}

1 Introdução. 2 O Consenso de Washington e as reformas neoliberais. 3 Reformas neoliberais no Brasil e na América Latina. 3.1 Reformas nos sistemas judiciais latino-americanos. 4 Reforma do poder Judiciário brasileiro de 2004. 4.1 A reforma do Judiciário brasileiro como reflexo das reformas neoliberais na América Latina. 5 Considerações finais. 6 Referências. 


\section{INTRODUÇÃO}

Após as crises econômico-financeiras de década de 70, uma série de mudanças na ordem econômica internacional começou a ser introduzida com base em um novo conjunto de ideias capitaneadas, principalmente, pelos Estados Unidos da América (EUA) e por organismos financeiros internacionais. A esse modelo político-econômico atribuiu-se, convencionalmente, o nome de neoliberalismo (BATISTA, 1994; RAMOS; DINIZ, 2014).

Entre as repercussões das ideias neoliberais nos países latino-americanos, os autores citados destacam as relevantes reformas nas suas estruturas estatais, com o objetivo de diminuir as competências atribuídas ao setor público - estas repassadas à iniciativa privada - promover a desregulamentação da atuação do capital na economia, bem como otimizar a eficiência daquilo que não pudesse ser privatizado.

Nesse sentido, as reformas dos sistemas judiciais da América Latina com o objetivo de combater, sobretudo, a morosidade das decisões e a insegurança jurídica receberam enfoque diferenciado por parte de organismos financeiros internacionais, a exemplo do Banco Mundial e do Banco Interamericano de Desenvolvimento (BID), tanto que vários relatórios técnicos de acompanhamento dessas reformas foram elaborados (DAKOLIAS, 1996; ROWAT et al., 1995; RIEGO RAMÍREZ, 2003, 2004; FAUNDEZ, 2002; RAMOS; DINIZ, 2014).

$\mathrm{O}$ artigo tem por objetivo analisar as influências dos conceitos neoliberais especificamente em relação à reforma do poder Judiciário brasileiro realizada em 2004, por meio da Emenda Constitucional (EC) n. 45, com o escopo de compreender as inovações que foram instituídas e as que não o foram.

Como referenciais teóricos a dar suporte ao presente trabalho foi utilizada a ideia, presente nos trabaIhos de Ramos e Diniz (2014) e de Faundez (2002), de que a reforma dos sistemas judiciais latino-americanos consistiu em uma das diversas etapas do ajuste neoliberal capitaneada na região por organismos financeiros - a exemplo do Fundo Monetário Internacional (FMI) e Banco Interamericano de Desenvolvimento (BID) que, em contrapartida aos empréstimos financeiros e às consultorias técnicas fornecidas, passaram a exigir mudanças na estrutura e no próprio papel dos Estados em tais países.

Assim, o presente artigo consiste em uma revisão sistemática, como uma espécie de revisão de literatura, tendo-se analisados estudos e pesquisas anteriores acerca da política macroeconômica neoliberal e suas diretrizes compiladas no evento conhecido como "Consenso de Washington".

Para tanto, ele encontra-se estruturado da seguinte maneira: a) análise do Consenso de Washington e das reformas neoliberais levadas a cabo, sobretudo, pelos EUA e por organismos financeiros internacionais; $b$ ) análise do conjunto de reformas políticas e econômicas neoliberais promovidas no Brasil e em outros países da América Latina; c) exame das reformas dos sistemas judiciais latino-americanos; d) análise da Reforma do Poder Judiciário brasileiro de 2004, por meio da EC n. 45; e) análise da reforma do poder Judiciário brasileiro como um reflexo das reformas neoliberais promovidas nos países da América Latina; f) por fim, as considerações finais sobre os resultados encontrados.

\section{O CONSENSO DE WASHINGTON E AS REFORMAS NEOLIBERAIS}

No final do ano de 1989 ocorreu em Washington, EUA, uma reunião entre representantes do governo norte-americano e de organismos financeiros internacionais especializados em matérias relativas à América Latina - a exemplo do Banco Mundial, do BID e do FMI, todos com sede na referida capital. Tal encontro objetivava avaliar as reformas econômicas realizadas nos países latino-americanos, e suas conclusões, posteriormente, passaram a ser denominadas, de modo extraoficial, de Consenso de Washington (BATISTA, 1994).

Batista (1994) prossegue e afirma que, apesar de seu caráter preponderantemente acadêmico - e não deliberativo - tal reunião cuidou de compilar uma série de exigências de reformas que citados organismos financeiros já vinham exigindo dos países da América Latina para lhes concederem cooperação financeira. Em suma, simbolicamente, compilou-se a "cartilha" neoliberal que os EUA vinham recomendando nos anos anteriores para a região, mas que se encontrava esparsa e em distintos documentos.

Desde o final da Segunda Guerra Mundial predominava a lógica universalista das políticas econômicas keynesianas e anticíclicas. Nas três últimas décadas do século 20, entretanto, ocorreu um processo de financeirização da economia capitalista mundial, associada a uma reestruturação das cadeias dos processos produ- 
tivos e a reforma do Estado com vistas a estimular o funcionamento livre do mercado (RIBEIRO, 2013). E, conforme descrito, os ideais neoliberais de combate ao modelo estatal intervencionista até então predominante foram compilados e ratificados no Consenso de Washington.

Capitaneada pelos governos Thatcher, na Inglaterra, e Reagan, nos EUA, referida doutrina político-econômica tinha os seguintes objetivos: a redução do tamanho agregado do setor público, a restrição dos gastos com políticas de bem-estar social, a redução da tributação e a elevação dos gastos com a área da defesa e com a garantia da lei e da ordem. Embora, em cada um dos governos, houvesse relevantes disparidades com relação à abordagem e à introdução, as similitudes existem e chamam a atenção (KING, 1988). De modo a complementar as informações sobre os objetivos dessa doutrina, veja-se o trecho a seguir transcrito:

Esses objetivos são influenciados por certas correntes de pensamento da "nova direita", o que em parte explica a caracterização popular desses dois governos através deste termo. As idéias da nova direita são basicamente uma revivescência do liberalismo clássico: uma crença no indivíduo, um papel limitado para o Estado nas questões sociais e econômicas e uma preferência por processos de mercado à provisão pública (KING, 1988, p. 72).

Determinados autores consideram que a doutrina político-econômica neoliberal representada no Consenso de Washington corresponde a uma faceta de um novo imperialismo exercido pelos EUA após a derrocada da URSS e o fim da guerra fria, com aquele país assumindo o papel de detentor de um poder de polícia internacional (HARDT; NEGRI, 2006). Tratar-se-ia de um imperialismo não baseado - somente - na força e no poderio militar, mas na gradativa inclusão dos diversos países ao bloco norte-americano sob o argumento da garantia da liberdade e da democracia (BAGNOLI, 2009).

Verificou-se, sobretudo a partir do período de crises vivenciado no início da década de 70, a necessidade de reorganização das relações políticas e econômicas interestatais, devendo tal processo ser conduzido pelo Estado hegemônico, responsável por estabelecer a moeda mundial, dinamizar a circulação de capitais e mercadoria no mercado global, regular os contratos e as relações entre Estados e indicar os limites da diplomacia, da paz e da guerra (MARTINS, 2007).

Ou seja, conforme afirma Martins (2007), diante da ameaça à hegemonia norte-americana ocorrida entre 1968 e 1973, os EUA reagiram por meio da financeirização do capital e do neoliberalismo. A partir da consequente drenagem da liquidez mundial, o citado país consegue retornar a uma taxa de crescimento superior à média mundial.

No mesmo sentido, Ribeiro (2013) aduz que a financeirização da economia capitalista resultou em um processo de descrédito das políticas públicas de caráter universalista - a exemplo dos sistemas de seguridade social - privilegiando políticas públicas focalizadas e, sobretudo, de combate à pobreza, pois estas comprometeriam parcelas significativamente menores do orçamento público e teriam resultados políticos mais concretos e imediatos. O mesmo autor, porém, argumenta que este segundo grupo de políticas não é capaz de promover reais modificações na estrutura de desigualdades e acaba apenas reproduzindo clientelismos arraigados na tradição política em razão de seu caráter residual.

Também foi mencionado anteriormente que, nesse contexto de reorganização do capital internacional e de reafirmação da influência norte-americana, houve a prescrição de medidas a serem efetivadas no âmbito da América Latina. Sobre a relação entre esse novo imperialismo financeiro norte-americano e as políticas internas dos países em desenvolvimento, Bagnoli (2009) observa que as instituições financeiras teoricamente internacionais são, muitas vezes, mantidas e controladas pelos EUA, ratificando esse imperialismo ao emprestarem recursos financeiros aos países em desenvolvimento para a execução de suas políticas internas.

Acerca da atuação das mencionadas instituições financeiras internacionais na questão do combate à pobreza na América Latina, Cardoso e Foxley $(2009$, p. 14) fazem as seguintes observações, destacando, inclusive, como o fornecimento de crédito a tais países ajuda na manutenção de sua liquidez financeira e facilita a aquisição de novos financiamentos externos junto ao setor privado:

América Latina ha logrado avances significativos en los últimos años para promover el crecimiento y reducir la pobreza. Estos logros deben ser protegidos; es por eso que instituciones multilaterales orientadas a la región - el Banco Interamericano de Desarrollo (BID), la Corporación Andina de Fomento (CAF) y el Fondo Latinoamericano de Reservas (FLAR) - han actuado acertadamente al ofrecer nuevas líneas de crédito, de manera 
de apoyar a los países que requieran este financiamiento. La mayor liquidez para los mercados financieros de nuestra región es fuertemente bienvenida para así enfrentar las dificultades transitorias en el acceso al financiamiento privado externo.

Já com relação aos impactos negativos dessa atuação, Portella Filho $(1994$, p. 130) afirma o que se segue:

Após a crise financeira de 1982, os organismos internacionais passaram a exercer forte pressão sobre os países devedores que atrasavam pagamentos aos bancos comerciais. A interferência do FMI e Bird contribuiu para tornar as negociações distorcidas em favor dos bancos, que submeteram os devedores latino-americanos a uma exação financeira massacrante. Enquanto os devedores tiveram que arcar com grandes sacrifícios econômicos, os bancos privados auferiram, em quase todos os anos da década de oitenta, lucros elevados.

Pode-se observar, então, após o fim da guerra fria e a derrocada da URSS, a formação de um novo quadro geopolítico e financeiro mundial, com os EUA assumindo o papel de protagonista e principal agente promotor dessa nova ordem recém-estabelecida, com o poder do capital financeiro constituindo uma de suas principais características. Na seção seguinte serão abordados os reflexos da política neoliberal nos países latino-americanos, sobretudo quanto às reformas promovidas por tais nações para se adequarem ao "modelo" prescrito pelo Consenso de Washington.

\section{REFORMAS NEOLIBERAIS NO BRASIL E NA AMÉRICA LATINA}

Com relação à América Latina, após o período de preponderância das ideias desenvolvimentistas promovidas pela Comissão Econômica para a América Latina e o Caribe (Cepal), a corrente de pensamento econômico neoliberal ganha espaço, opondo-se às ideias da Cepal e ignorando as preocupações sociais apresentadas pelos desenvolvimentistas até aquele momento (SOUSA, 2011).

Dessa forma, passou-se a exigir dos países da região latino-americana a realização do conjunto de reformas já mencionado: disciplina fiscal, redução dos gastos públicos, reforma tributária, juros de mercado, câmbio de mercado, abertura comercial, investimento estrangeiro direto com eliminação de restrições, privatização das estatais, desregulamentação (afrouxamento das leis econômicas e trabalhistas) e direito à propriedade intelectual.

Portella Filho (1994), sobre os sacrifícios exigidos pelos países devedores da América Latina, afirma que eles foram encorajados a buscar, ao mesmo tempo, o pagamento total da dívida, a abertura de seus mercados ao modelo liberal e a estabilização de suas economias. Consequentemente, ao perseguirem três metas simultaneamente, acabaram por se deparar com um ajustamento de difícil execução técnica e política, com base em medidas quase sempre radicais e de resultados no curto prazo. Ainda nesse assunto:

O país endividado negociava um programa de ajustamento contendo políticas macroeconômicas do FMI e reformas setoriais orientadas pelo Bird. Os programas de ajustamento do FMI mudaram pouco desde o início da crise da dívida até os dias de hoje. Eles tentavam e continuam tentando reduzir o déficit do balanço de pagamento via contenção da demanda interna. O peso dos sacrifícios é concentrado no governo e nas estatais. As chamadas "necessidades de financiamento do setor público" devem ser cortadas ao meio, de preferência mediante redução de gastos e não aumento de receitas. Ao mesmo tempo, o governo precisa liberalizar a economia. Os controles de preços precisam ser relaxados ou abolidos (mesmo os de setores oligopolizados) para melhor alocação de recursos (PORTELLA FILHO, 1994, p. 107).

Faundez (2002), analisando os motivos que impulsionaram as reformas legais e judiciais na região, elenca três estímulos a esse processo: a) as novas políticas econômicas, embasadas em princípios de mercado que exigem a modernização de instituições ultrapassadas e a criação de outras; b) a extensão da democracia na região, que demonstrou às elites a importância da estabilidade dos marcos políticos e legais; c) e as violações generalizadas de direitos humanos durante as décadas anteriores, que destacaram a importância da existência de mecanismos confiáveis e eficazes de controle dos governos. 
Além do destaque a esses fatores, o autor também aponta para o papel de organizações internacionais como o Banco Mundial, o Pnud e BID no apoio, na promoção e na condução dos processos de reforma legal e judicial levados a cabo nos países da região. Faundez (2002) aponta para o montante de U\$ 435.000.000,00 investidos, de 1993 a 1999, em operações de assistência técnica com o objetivo de promover tais reformas em 18 dos 26 países membros do BID .

No caso brasileiro, a seguinte passagem de Pochmann (2007, p. 1.478) descreve as bases do nosso país e como este se inseria no contexto global quando do início das reformas neoliberais na região:

Em países periféricos como o Brasil, a desigualdade constituída ainda pela condição colonial, marcada pelo extensivo uso escravo do trabalho, da monocultura da produção e do monopólio da terra, foi sendo consolidada pelo avanço do capitalismo selvagem. Sem a realização das reformas civilizadoras, o fantástico progresso das forças produtivas ocorrido no ciclo da industrialização nacional (1933-1980) seguiu contaminado pela dinâmica da exclusão. Com a crise da dívida externa (1981-1983), que estancou o projeto de industrialização nacional, e a adoção de políticas neoliberais desde 1990, ganhou ênfase o processo de financeirização da riqueza, sustentada fundamentalmente pelo endividamento do Estado. Em torno disso formou-se, a partir do Plano Real (1994), uma convergência política que, ao combinar a estabilidade monetária com a valorização dos ativos financeiros, terminou recorrentemente asfixiando a retomada sustentada do desenvolvimento nacional.

Cabe ressaltar que, após a primeira onda de reformas concluída no início da década de 90, não foram constatados maiores ganhos por parte das populações locais em termos de condições de vida. A partir do ponto em que o mercado tornou-se o único responsável por repartir os recursos, a desigualdade social intensificou-se. Aos ricos, aumento na capacidade de consumo; aos pobres, sua redução. A partir das medidas neoliberais do Consenso de Washington, aqueles sem acesso a recursos básicos passaram a uma condição ainda pior (RAMOS; DINIZ, 2014).

Nas reformas neoliberais de segunda geração, em momento posterior, competiria ao ente estatal realizar as reformas necessárias nos seguintes setores: sistema educacional, saúde, previdência, sistema político e judiciário, direitos de propriedade e legislação trabalhista (RAMOS; DINIZ, 2014). No próximo tópico serão abordadas as reformas promovidas e incentivadas especificamente nos sistemas judiciais dos países da América Latina.

\subsection{Reformas nos sistemas judiciais latino-americanos}

Especificamente com relação ao poder Judiciário de tais países, verificou-se uma série de reformas promovidas, sendo, inclusive, acompanhadas de modo detalhado por organismos financeiros internacionais, a exemplo do Banco Mundial. Em documento técnico de acompanhamento dessas reformas publicado em 1996, estão presentes as seguintes afirmações deste organismo:

Os países na América Latina e o Caribe estão emergindo de um período de grandes mudanças e ajustes. Essas mudanças recentes têm causado uma reformulação do papel do Estado. Tem havido uma maior dependência dos mercados e do setor privado, atuando o Estado como um importante elemento para facilitar e regular a atividade e o desenvolvimento do setor privado. Sem embargo, as instituições públicas na região não têm conseguido responder de maneira efetiva a estes desafios. Com a finalidade de apoiar e estimular um desenvolvimento sustentável e equitativo, os governos latino-americanos e caribenhos se encontram dedicados à formação institucional capaz de proporcionar maior eficiência, autonomia funcional e serviços melhorados. 0 poder judicial é uma instituição pública necessária que deve promover aos cidadãos, agentes econômicos e ao Estado a resolução equitativa, diligente e transparente das controvérsias. Sem embargo, em muitos países da região existe a necessidade de reformas a fim de melhorar a qualidade e eficiência da administração da Justiça. Isto, por sua vez, estimulará um clima habilitante que facilite o comércio, o financiamento e a inversão (DAKOLIAS, 1996, p. V, tradução livre).

A partir do posicionamento de tais organismos financeiros internacionais em relação ao poder Judiciário dos países da América Latina, fica nítida a compreensão das instituições judiciárias nacionais como relevantíssimos fatores econômicos capazes de viabilizar ou de comprometer seriamente a expansão dos capitais financeiros ali investidos. Isso justifica não só o acompanhamento em relação às reformas realizadas, mas também seu estímulo nos países que ainda não a houvessem iniciado. 
Faundez (2002) ratifica esse entendimento ao defender que a preocupação do BID com a reforma judicial nos países da região começou quando funcionários da instituição compreenderam como os objetivos de desenvolvimento econômico frequentemente são frustrados em decorrência de falhas e debilidades das instituições legais. As novas políticas econômicas voltadas ao mercado e instituídas na região são influenciadas pelo fator jurídico-judicial, o que destaca a importância do Direito em seu papel de regulador da economia de mercado.

Faundez (2002), entretanto, alerta que, mesmo com a legitimidade de atuação do BID na temática de reforma dos sistemas legais latino-americanos não sendo alvo de maiores questionamentos, uma má condução desse processo poderia levar a diversas consequências negativas. Tal atuação necessitaria de extrema cautela e só seguiria sendo legítima se contribuísse para o fortalecimento dos sistemas políticos locais e para o desenvolvimento da região.

Em relatório técnico oriundo da Conferência do Banco Mundial para a Reforma Judicial na América Latina e Caribe de 1994, tal órgão afirma que um poder Judiciário efetivo e capaz de reforçar o Estado de Direito deve ser forte, independente e ter operações de alta qualidade. Em suma, deve ser eficiente, cabendo frisar o destaque conferido a esta terminologia (ROWAT et al., 1995).

O documento também assevera que uma reforma judicial para aprimorar a qualidade e a eficiência do sistema de Justiça normalmente engloba: a) racionalização das leis e procedimentos; b) melhora na administração dos tribunais; c) capacitação dos servidores, magistrados e demais operadores do Direito; d) fortalecimento da independência dos juízes; e) estímulo aos meios alternativos de resolução de conflitos; f) balanceamento dos custos do Judiciário e expansão do acesso à Justiça aos pobres (ROWAT et al., 1995).

Ramos e Diniz (2014), ao abordarem o padrão de sistema de Justiça buscado por meio dessas reformas, asseveram que se defendia uma maior previsibilidade nas decisões, diminuindo ou mesmo eliminando os riscos aos investimentos, ao mesmo tempo que permaneceria assegurada a independência funcional, garantindo que o Judiciário estivesse subordinado ao Estado de Direito e não às influências políticas.

As citadas autoras prosseguem e afirmam que a eficiência do Judiciário permaneceu em destaque nas reformas, traduzindo-se na capacidade estatal de dirimir os conflitos de forma rápida e justa. Por fim, mais alguns elementos são destacados por elas: a transparência, estimulando o controle social da Justiça e fortalecendo o combate à corrupção; a proteção à propriedade privada e aos contratos como bases imperativas da lógica do mercado e os métodos alternativos de solução de conflitos, estimulando o Judiciário a se aperfeiçoar cada vez mais.

Entre as metas a serem alcançadas por meio desse conjunto de reformas, conforme pode ser percebido dos objetivos supracitados, destacam-se o combate à morosidade dos órgãos jurisdicionais - uma vez que a demora na resolução dos conflitos acaba por comprometer o próprio resultado útil do processo - e a falta de previsibilidade nas decisões do Judiciário, o que gera insegurança nos agentes econômicos e, por conseguinte, mais custos decorrentes desse risco.

Pode ser citado o caso do Peru como exemplo de um país latino-americano no qual se desenvolveram alterações com o intuito de promover, na condição de sistema paralelo ao jurídico-processual, os meios alternativos de resolução de conflitos. No ambiente da denominada "Justiça de Paz" peruana, composta predominantemente por pessoas leigas, aqueles responsáveis por conciliar as partes na busca de uma solução para o litígio são eleitos pelo voto popular - isso desde a nova Constituição de 1993 (ROWAT et al., 1995).

Citado relatório prossegue e afirma que tal forma de escolha dos juízes de paz aumenta a confiança depositada pela população naqueles eleitos para o cargo, o que também amplia o controle social exercido sobre a instituição. A nova legislação peruana acerca da matéria, inclusive, atribui poderes jurisdicionais limitados - em determinadas hipóteses taxativas, embora tenha permanecido a dispensa de embasamento jurídico-formal nas decisões proferidas pelos juízes de paz. A legislação apenas exige que as suas sentenças sejam fundamentadas em uma análise honesta dos fatos apresentados pelas partes e respeitem os valores previstos na Constituição peruana, cultura e costumes locais.

A seguir será analisada, de modo mais detido, a reforma promovida no poder Judiciário brasileiro a partir da EC no 45/04. 


\section{REFORMA DO PODER JUDICIÁRIO BRASILEIRO DE 2004}

Em 8 de dezembro de 2004, em meio a diversas Propostas de Emenda à Constituição (PEC) que abordavam o poder Judiciário, foi aprovada a EC no 45/04, que promoveu diversas alterações na estrutura organizacional desse poder da República, a exemplo da criação do Conselho Nacional de Justiça (CNJ) como órgão administrativo e disciplinar, além de positivar o direito fundamental à razoável duração do processo no artigo 5, LXXVIII, da Constituição Federal (CF) de 1988.

O cenário nacional imediatamente anterior à aprovação da EC no 45/04 indicava um descontentamento generalizado com a lentidão do poder Judiciário ao exercer a Jurisdição para solucionar os conflitos sociais levados a ele. A citação a seguir, de Andrade (2006, p. 178), descreve esse ambiente em que se deram os debates acerca da temática.

O ambiente político, social e econômico que envolveu o demorado trâmite do processo legislativo dessa emenda constitucional apontou no sentido unívoco de crítica generalizada à chamada morosidade da Justiça e do poder Judiciário. Seguramente há mais de uma década as críticas, de especialistas e leigos, à demora do poder Judiciário em definir as questões colocadas em lides levadas ao seu conhecimento vinham aumentando exponencialmente. Tanto especialistas da área jurídica como leigos e jornalistas, todos eram unânimes em afirmar a deficiência do poder Judiciário, aparentemente incapaz de assegurar com presteza e efetividade a defesa dos direitos violados levados à sua apreciação.

Tamanha era a preocupação com a morosidade do Judiciário que, conforme referido anteriormente, o Congresso Nacional julgou necessário estabelecer expressamente o direito à razoável duração do processo na CF de 1988, apesar de doutrinadores como Mendes e Branco (2017) afirmarem que se tratou apenas do estabelecimento formal de um direito que já estaria presente no ordenamento jurídico nacional, contido implicitamente na ideia de proteção judicial efetiva.

Com relação aos mecanismos de controle interno do poder Judiciário, a EC no 45/04 promoveu grande alteração ao estabelecer a criação do CNJ no artigo 103-B da CF. Nos termos do §4ㅇ deste artigo, compete "ao Conselho o controle da atuação administrativa e financeira do poder Judiciário e do cumprimento dos deveres funcionais dos juízes" (BRASIL, 1988), entre outras atribuições, de modo que passou a haver um órgão de âmbito nacional com competência para controlar internamente a atuação dos órgãos do Judiciário.

Tal modificação gerou fortes críticas e repercussões por parte dos magistrados e de suas respectivas associações representativas, tanto que a Associação dos Magistrados Brasileiros (AMB) propôs a ADI 3.367, alegando suposta ofensa ao princípio federativo (artigo $2 \circ$ da CRFB) com a criação do CNJ e com sua competência de fiscalização sobre as Justiças estaduais. O STF, contudo, de acordo com a ementa a seguir, declarou a constitucionalidade do referido órgão de controle interno:

Ação direta. EC 45/2004. Poder Judiciário. CNJ. Instituição e disciplina. Natureza meramente administrativa. Órgão interno de controle administrativo, financeiro e disciplinar da magistratura. Constitucionalidade reconhecida. Separação e independência dos poderes. História, significado e alcance concreto do princípio. Ofensa à cláusula constitucional imutável (cláusula pétrea). Inexistência. Subsistência do núcleo político do princípio, mediante preservação da função jurisdicional, típica do Judiciário, e das condições materiais do seu exercício imparcial e independente (ADI 3.367, rel. min. Cezar Peluso, J. 13-4-2005, P. DJ de 22-9-2006).

Entre as atribuições previstas no artigo 103-B, §4ํ, da CF, destaca-se o inciso VI, que prevê a competência do CNJ para elaborar semestralmente relatório estatístico sobre processos e sentenças prolatadas, por unidade da Federação, nos diferentes órgãos do poder Judiciário. A partir desse dispositivo fica nítida a influência do direito à razoável duração do processo na própria estrutura do poder Judiciário, pois a reforma criou um órgão administrativo e disciplinar com competência para analisar a questão do acúmulo de processos em todos os órgãos jurisdicionais brasileiros.

Ao mesmo tempo, a criação do CNJ buscou mudar o aspecto fechado do poder Judiciário, com a sociedade pouco tendo acesso a maiores informações acerca de seu funcionamento e de sua lógica. Almejou-se, em suma, introduzir o conceito norte-americano de accountability no sistema judicial, competindo a esse novo órgão direcionar a mudança de postura por parte dos Tribunais de todo o país (TOMIO; ROBL FILHO, 2013). 
O controle disciplinar merece destaque, uma vez que o CNJ passou a monitorar a atuação dos membros e órgãos da magistratura brasileira, inclusive em relação a seus serviços auxiliares, serventias e órgãos prestadores de serviços notariais e de registro que atuem por delegação do poder público ou oficializados, sem prejuízo da competência disciplinar e correcional dos tribunais, podendo avocar processos disciplinares que estejam em curso nas Corregedorias dos Tribunais das diversas Justiças do ordenamento brasileiro. Ressalte-se que tal competência somente não pode ser exercida em face do próprio STF, que ocupa o posto de órgão de cúpula de todo o poder Judiciário (MENDES; BRANCO, 2017).

Com essas competências atribuídas ao CNJ, houve inegáveis avanços na questão da abertura do poder Judiciário à sociedade e do dever de accountability de suas atividades, dado que não pode existir e não é adequada uma independência judicial institucional plena, conforme apontam Tomio e Robl Filho (2013), destacando-se o fato de que $40 \%$ dos conselheiros que compõem o órgão não são provenientes da magistratura (quatro são profissionais das funções essenciais à jurisdição, no caso, advogados e membros do MP, e dois são cidadãos de notável saber jurídico).

Apesar das evidentes novidades positivas trazidas com a criação e a estruturação do CNJ, a questão da morosidade e do acúmulo de processos ainda existe e é gravíssima, com milhões de processos aguardando julgamento conforme relatórios do próprio órgão (BRASIL, 2017), bem como persiste o sentimento de impunidade pelo frouxo combate à corrupção dentro do próprio poder Judiciário.

Outro ponto abordado de forma incisiva pela Reforma do Judiciário Brasileiro foi a questão da uniformização das decisões judiciais, de modo a combater o "decisionismo" e a falta de previsibilidade no momento de promoção de uma demanda. A inovação que mais chamou a atenção nesse aspecto foi a criação das denominadas Súmulas Vinculantes, instituto até então inexistente em nosso ordenamento.

De acordo com o artigo 103-A, compete ao STF, de ofício ou por provocação, mediante decisão de dois terços dos seus membros, após reiteradas decisões sobre determinada matéria constitucional, aprovar enunciado de súmula que, a partir do momento de sua publicação oficial, terá efeito vinculante em relação aos demais órgãos do Judiciário e à administração pública direta e indireta, nas esferas federal, estaduais e municipais, competindo-lhe também proceder à sua revisão ou cancelamento, na forma estabelecida em lei (BRASIL, 1988).

As súmulas vinculantes, a partir de sua criação, passaram a ser editadas justamente com o propósito de solucionar controvérsias entre órgãos jurisdicionais acerca da validade, interpretação ou eficácia de determinada norma que estejam provocando grave insegurança jurídica e multiplicando processos sobre idêntica questão. Inclusive foi previsto o cabimento de reclamação constitucional para anular ato administrativo ou cassar decisão judicial que contrarie ou que indevidamente aplique enunciado de súmula vinculante do STF.

Nota-se o objetivo, com a edição de tais súmulas, de racionalizar as decisões do poder Judiciário, uniformizando a jurisprudência sobre assuntos controvertidos e evitando o excesso de demandas judiciais em torno deles. De modo reflexo, combater-se-ia a própria morosidade, uma vez que demandas propostas em torno de matérias já pacificadas por esse meio seriam rapidamente solucionadas com a simples aplicação do conteúdo sumulado pelo STF. Por outro lado, Silva (2016, p. 572), contestando a efetividade do instituto para alcançar tais metas, afirma que:

Como se viu, as súmulas vinculam não só os órgãos do poder Judiciário, mas também os órgãos da Administração Pública direta e indireta, nas esferas federal, estadual e municipal, e, assim, tolhem uma correta apreciação das alegações de lesão ou ameaça de direito que está na base do direito de acesso à Justiça, sem que se veja como elas podem reduzir o acúmulo de feitos perante o Supremo Tribunal Federal, pois só nesse âmbito têm aplicação. Não parecem reduzir os recursos, pois está previsto que, se o ato administrativo ou a decisão judicial contrariar a súmula aplicável, caberá reclamação para o Supremo Tribunal Federal que, julgando-a procedente, anulará o ato administrativo ou cassará a decisão reclamada, e determinará que outra seja proferida com ou sem a aplicação da súmula, conforme o caso (art. 103-A, §3ㅇ․). Na verdade, há uma mera troca de meios de impugnação: reclamação em vez de recurso ordinário ou extraordinário. Parece-nos que têm pouca utilidade relativamente ao âmbito da interpretação constitucional, para a qual está previsto o efeito vinculante (infra). 
Houve ainda a alteração do $2^{\circ}$ do artigo 102 da CF, que passou a estabelecer efeitos vinculantes e eficácia erga omnes relativamente aos demais órgãos do poder Judiciário e à administração pública direta e indireta nas três esferas federativas para as decisões definitivas de mérito proferidas pelo STF tanto em sede de ação declaratória de constitucionalidade quanto de ação direta de inconstitucionalidade.

Outra inovação processual estabelecida com o objetivo de combater o excessivo número de recursos interpostos perante o STF foi a necessidade de demonstração de repercussão geral das questões constitucionais discutidas em sede de recurso extraordinário apresentado perante esta Corte, com base no artigo 102, §3으, da $\mathrm{CF}$, competindo-lhe examinar este requisito de admissibilidade recursal.

Nota-se, por conseguinte, a busca por mudanças no papel do STF, tornando-o cada vez mais uma Corte Constitucional, que passa, nas palavras de Medina e Wambier (2013), a ser responsável por julgar assuntos que transcendem os limites subjetivos da causa, indo para além dos interesses das partes. Pretende-se, assim, reduzir o acúmulo de recursos que acabam por transformar a Suprema Corte brasileira em autêntico Tribunal de terceira ou mesmo de quarta instância.

Após os pontos alterados pela EC n. 45/04 no poder Judiciário citados anteriormente, passa-se a analisar como tais mudanças relacionam-se com o conjunto de reformas promovidas nos países latino-americanos e capitaneadas, principalmente, pelos EUA e por organismos financeiros internacionais ali sediados.

\subsection{A Reforma do Judiciário Brasileiro como reflexo das reformas neoliberais na América Latina}

Apesar de a Reforma Administrativa promovida no Brasil por meio da EC n. 19/98 ter sido aprovada anos antes da EC n. 45/04, responsável pela reforma do poder Judiciário, esta última tramitou por mais de dez anos no Congresso Nacional, compondo o conjunto de PECs apresentado e discutido durante a década de 90 com o objetivo de promover amplas alterações no Estado brasileiro.

Nohara (2012), ao comparar as duas reformas, conclui que a busca por uma maior eficiência correspondeu a um dos principais pontos instituídos por ambas, tanto que o princípio da eficiência passou a compor expressamente o rol de princípios da Administração Pública do artigo 37 da Constituição Federal de 1988. Com relação à Reforma do Judiciário, porém, a eficiência almejada dizia respeito, sobretudo, ao aspecto temporal, ou seja, à celeridade processual.

Em decorrência do extenso rol de direitos positivados na CF de 1988 e do progressivo acesso das camadas menos favorecidas ao sistema de Justiça, este passou a ser cada vez mais acionado para concretizar as normas constitucionais previstas abstratamente. $E$, por não estar estruturalmente preparado para tamanho aumento no número de demandas, o Judiciário acabou sofrendo fortes pressões nos primeiros anos após a promulgação da CF em decorrência da morosidade de suas decisões (NOHARA, 2012).

Então, entre as medidas estabelecidas pela EC n. 45/04, conforme mencionado, foi incluído, no artigo 5o da CRFB, o inciso LXXVIII, prevendo que: "a todos, no âmbito judicial e administrativo, são assegurados a razoável duração do processo e os meios que garantam a celeridade de sua tramitação" (BRASIL, 1988).

De plano, foi louvável a intenção do Congresso Nacional em tentar reverter a morosidade na resolução dos processos judiciais, indiscutivelmente um dos principais problemas do poder Judiciário a serem combatidos. Tanto é que a análise da questão da morosidade constitui uma das principais atividades do CNJ desde sua instituição.

A tentativa de uniformização das decisões judiciais em determinados assuntos, da mesma maneira, se bem conduzida, poderia trazer consideráveis benefícios na concretização do princípio da segurança jurídica ao racionalizar o processo decisório jurisdicional, impedindo que casos que versem sobre a mesma temática sejam decididos de forma diferente sem a devida justificação.

Também merece menção o aprimoramento na denominada accountability institucional interna do sistema de Justiça por meio da criação do CNJ, quebrando com o anterior modelo em que as fiscalizações administrativa, disciplinar, orçamentária e financeira dos órgãos e membros do poder Judiciário eram realizadas somente pelas Corregedorias dos respectivos Tribunais (TOMIO; ROBL FILHO, 2013). 
Pode-se afirmar que a reforma gerencial promovida no Estado brasileiro em 1998 por meio de EC n. 19 teve a sua complementação no campo jurisdicional realizada por intermédio da EC n. 45 após cinco anos da promulgação da primeira (NOHARA, 2012). Assim, estaria concluída uma importante etapa na busca por um Estado embasado no princípio da eficiência a partir de práticas de gestão administrativa e da necessidade de o Judiciário prestar contas de suas atividades, justificando à sociedade os altos custos com sua manutenção.

Mesmo, no entanto, após mais de uma década de aprovação da EC n. 45/04, constata-se, pelos relatórios do CNJ, que o número de novas ações judiciais propostas no Brasil não para de crescer. Em relatório sobre o número de processos que tramitaram no ano de 2014 no Brasil, o CNJ informou que se chegou a um total de 99,7 milhões de processos, dos quais 91,9 milhões só na 1a Instância. E, o que é mais estarrecedor, a capacidade produtiva anual do poder Judiciário brasileiro de 1 o grau é de apenas $27 \%$ da demanda total, que inclui os casos novos e o acervo já existente (BRASIL, 2017). A transcrição a seguir do relatório explicita melhor a situação entre as diferentes Justiças:

O fenômeno da maior sobrecarga de trabalho no primeiro grau se repete em todos os segmentos do Judiciário, embora seja menor na Justiça Federal, cuja taxa de congestionamento é mais equilibrada entre primeiro e segundo graus (excluídos os juizados especiais e turmas recursais): $78 \%$ e $66 \%$, respectivamente. De outro lado, dados do Relatório Justiça em Números igualmente demonstram que, apesar da excessiva carga de processos, a força de trabalho disponibilizada ao primeiro grau (servidores) é, proporcionalmente, inferior à dedicada ao segundo. Como consequência, os servidores de primeiro grau estão mais sobrecarregados. Basta dizer que, considerando todo o Judiciário, a carga de trabalho por servidor da área judiciária é de 506 processos no primeiro grau e de 232 no segundo, diferença de 118\%. Na Justiça Estadual essa desproporção é ainda maior: 563 processos por servidor de primeiro grau contra 245 de segundo (129\%). A quantidade de servidor por magistrado também confirma essa distorção. Apesar de a carga de trabalho sobre os magistrados de primeiro grau ser $6 \%$ superior, o número de servidores da área judiciária por magistrado de segundo grau é $9 \%$ superior: 14 servidores por magistrado no segundo grau e 13 no primeiro. Essa desproporção é mais acentuada na Justiça Federal, na qual existem 26 servidores por magistrado de segundo grau e apenas 11 por magistrado de primeiro (130\% de diferença) (BRASIL, 2017).

Cabe ressaltar, porém, que compete ao poder Judiciário, em primeiro lugar, a resolução dos conflitos sociais a ele apresentados e a realização da Justiça por meio do exercício da Jurisdição. Desse modo, de nada valerão decisões proferidas de modo célere, mas construídas apenas com base em critérios e modelos predefinidos, pois elas não serão adequadas às particularidades existentes em cada caso concreto e não solucionarão o litígio de forma satisfatória.

O uso indiscriminado dos mecanismos de uniformização jurisprudencial trazidos pela EC n. 45/04, da mesma forma, pode levar a um engessamento do magistrado no momento de prolação de suas decisões, bem como comprometer sua necessária independência decisional e consequentemente o princípio do livre convencimento motivado. Como asseveram Ramos e Diniz (2014), o modelo de reformas dos sistemas judiciais latino-americanos promovido pelo Banco Mundial deixou de levar em consideração as especificidades de cada Estado, sobrepondo-se às garantias sociais indispensáveis à construção de uma sociedade democrática.

Passou-se, então, a perceber que novas modificações seriam necessárias para, de modo efetivo, promover o direito à razoável duração do processo ao se combater a lentidão no julgamento das causas. Entre as novas possibilidades levantadas destaca-se o uso dos meios alternativos de resolução de conflitos, que, desde a década de 90, vêm recebendo maior atenção nas reformas judiciais de outros países da América Latina.

O próprio documento técnico do Banco Mundial supracitado (ROWAT et al., 1995) afirma expressamente que qualquer reforma de um sistema judicial que busque eficiência e qualidade na prestação jurisdicional deve incluir a adoção de tais mecanismos no funcionamento do poder Judiciário. Conforme mencionado anteriormente, ao tratar da chamada "Justiça da Paz" no Peru como experiência com o uso da conciliação, o relatório afirma o seguinte:

A justiça da paz não jurisdicional representa uma alternativa ao sistema formal. Este meio de resolução de conflitos, administrado por cidadãos que não são profissionais do ramo jurídico, é bastante popular. Litigantes buscam um fórum em que eles possam falar sua própria língua e um juiz que irá compreender seus valores 
culturais e os problemas sociais da população local. No seu melhor, o sistema da justiça da paz evita processos formais e armadilhas procedimentais, resolve os conflitos em um curto período de tempo, é menos oneroso, e se beneficia de juízes que são honestos e justos (ROWAT et al., 1995, p. 92, tradução livre).

No caso da Reforma do Judiciário brasileiro, conforme se depreende da análise do conteúdo da EC $\mathrm{n}$. 45/04, as palavras conciliação, mediação e arbitragem sequer são mencionadas, excetuando-se a citação, no artigo $114, \S 2 \circ$, da arbitragem trabalhista nas questões que podem ensejar o ajuizamento de dissídio coletivo de natureza econômica perante a Justiça do Trabalho (BRASIL, 1988).

Em outros países da América Latina enxergou-se, ao se reformar o sistema judicial, a necessidade de ir para além do próprio Poder Judiciário, estabelecendo e fortalecendo meios não judiciais de resolução dos conflitos sociais e incorporando-os, na medida do possível, ao próprio procedimento adotado nos processos judiciais.

Após mais de dez anos da promulgação da EC n. 45, o novo Código de Processo Civil (CPC) brasileiro (Lei n. 13.105/2015) trouxe relevantíssimas alterações nesse sentido ao afirmar que, em seu artigo 3o, §3o, não obstante o princípio processual da inafastabilidade da apreciação jurisdicional de ameaça ou lesão a direito, a conciliação, a mediação e os demais métodos de solução consensual de conflitos deverão ser estimulados pelos operadores do Direito - juízes, advogados, defensores públicos e membros do Ministério Público - inclusive no curso do processo judicial.

Daí se depreende que, apesar da existência da Lei de Arbitragem (Lei n. 9.307/1996) desde a década de 90 e da política do CNJ de valorização do sistema "multiportas" de solução dos litígios, que deu origem ao Movimento pela Conciliação/CNJ de 2006 e à própria Semana Nacional de Conciliação, a Reforma do Judiciário brasileiro somente foi complementada no que se refere a esses mecanismos após mais de uma década, quando o novo CPC, aprovado e publicado em 2015, ampliou consideravelmente a importância de tais figuras no processo.

No que tange à mediação entre particulares como meio de solução de controvérsias e à autocomposição de litígios no âmbito da administração pública, foi sancionada a Lei n. 13.140/15 com o objetivo de regulamentar tais institutos neste momento de valorização e de destaque dos meios alternativos de solução de demandas.

Após tais considerações, pode-se, então, inferir que a Reforma do Poder Judiciário brasileiro de 2004, no intuito de aprimorar o sistema de Justiça na condição de relevante fator na garantia de segurança jurídica e boa condução dos negócios e investimentos no país, acabou por não observar um aspecto imprescindível a uma reforma que busque ser realmente efetiva: a valorização e a institucionalização dos meios alternativos de resolução de demandas.

A importância dos meios não judiciais de resolução de conflitos já vinha sendo destacada nos ordenamentos jurídicos de algumas nações da região latino-americana e do Caribe quando da reforma de 2004, o que deve servir de exemplo para o Brasil na sua busca por um sistema de Justiça mais acessível, mais célere, mais efetivo e, por fim, mais justo.

\section{CONSIDERAÇÕES FINAIS}

Com o cenário de crise econômica ocorrido nos anos 70, os EUA, em conjunto com a Inglaterra e organismos financeiros internacionais, passaram a adotar uma série de medidas em relação aos países latino-americanos que possuíam vultosas dívidas com tais instituições, com tais medidas sendo orientadas por um conjunto de princípios que ficou conhecido como "Consenso de Washington" (BATISTA, 1994).

Conforme foi demonstrado, esses organismos financeiros ligados aos interesses norte-americanos deram início a movimentos de pressão para que as nações da região aprovassem diversas mudanças e ajustes em seu interior, criando ambientes mais favoráveis aos investimentos externos. Entre essas mudanças destacou-se a reforma dos sistemas judiciais latino-americanos (FAUNDEZ, 2002; RAMOS; DINIZ, 2014).

Ao promover tais objetivos, o Banco Mundial, em seu modelo padronizado de reformas dos sistemas judiciais latino-americanos, deixou de levar em consideração as especificidades encontradas nos diversos países da região, conforme apontado por Ramos e Diniz (2014), o que prejudica a efetivação de tais reformas e compromete seu objetivo de busca por maior eficiência. 
No caso brasileiro, apesar dos importantes pontos modificados pela reforma de 2004 com o objetivo de combater a morosidade do poder Judiciário e o excesso de demandas e de recursos a ele apresentados, conclui-se que a EC n. 45/04, ao focar na efetividade e na razoável duração do processo, promoveu alteração apenas do ponto de vista formal, permanecendo a mesma lógica conflituosa e deixando de abordar, por exemplo, os meios alternativos de resolução de conflitos.

Somente nos últimos anos esses mecanismos passaram a receber o devido destaque por parte do poder Legislativo brasileiro, sendo amplamente inseridos no ordenamento jurídico nacional por meio do novo CPC de 2015 e regulamentados mediante normas específicas, como a Lei n. 13.140/2015.

Com relação ao CNJ, cumpre destacar os relevantes avanços com relação à abertura do poder Judiciário e ao dever de accountability de seus órgãos com a criação de mais um mecanismo de controle interno, mas os graves problemas de excesso de demandas, morosidade e insatisfação por parte dos jurisdicionados permanecem após mais uma década da sua criação.

Por conseguinte, pode-se atestar o caráter restritivo da EC n. 45/04 e da reforma por ela promovida no âmbito do Judiciário brasileiro, uma vez que não houve a preocupação em abordar tais institutos alternativos nos dispositivos constitucionais modificados. Buscou-se a solução para a morosidade na resolução de demandas somente dentro do próprio sistema Judiciário, olvidando-se o constituinte reformador de buscar respostas fora da formalidade do processo judicial, o que poderia ter sido diferente se as especificidades do Judiciário brasileiro tivessem sido consideradas quando da sua reestruturação em 2004.

\section{REFERÊNCIAS}

ANDRADE, Fábio Martins de. Reforma do Poder Judiciário: aspectos gerais, o sistema de controle de constitucionalidade das leis e a regulamentação da súmula vinculante. Revista de Informação Legislativa, Brasília, a. 43, n. 171, p. 177-197, jul./set. 2006.

BAGNOLI, Vicente. Direito e poder econômico. Rio de Janeiro: Elsevier, 2009.

BATISTA, Paulo Nogueira. O Consenso de Washington: a visão neoliberal dos problemas latino-americanos. Programa Educativo Dívida Externa - Pedex. Caderno Dívida Externa, n. 6, 2. ed., nov. 1994.

BRASIL. Código de Processo Civil. 16 de março de 2015. Disponível em: http://www.planalto.gov.br/ccivil_03/_ato20152018/2015/lei/l13105.htm. Acesso em: 10 jul. 2017.

BRASIL. Constituição da República Federativa do Brasil. 5 de outubro de 1988.

Disponível em: https://www.planalto.gov.br/ccivil_03/constituicao/constituicao.htm.

Acesso em: 20 maio 2017.

BRASIL. Poder Judiciário. Conselho Nacional de Justiça. Priorização do 1o grau da Justiça. 2017. Disponível em: http://www.cnj. jus.br/programas-e-acoes/politica-nacional-de-priorizacao-do-1-grau-de-jurisdicao/dados-estatisticos-priorizacao. Acesso em: 15 jun. 2017.

CARDOSO, Fernando Henrique; FOXLEY, Alejandro. Nuevos desafíos de la democracia y del desarrollo en América Latina. In: CARDOSO, Fernando Henrique; FOXLEY, Alejandro (org.). A medio camino: nuevos desafíos de la democracia y del desarrollo en América Latina. Santiago do Chile: Uqbar Editores, 2009.

CEPAL. Panorama económico y social de la Comunidad de Estados Latinoamericanos y Caribeños. 2016. Disponível em: http:// repositorio.cepal.org/bitstream/handle/11362/40916/1/S1601359_es.pdf. Acesso em: 13 abr. 2017.

DAKOLIAS, Maria. El sector judicial en América Latina: elementos da reforma. World Bank Technical Paper, Washington, D.C., n. 319, June, 1996.

FAUNDEZ, Alan Angell y Julio. Reforma judicial en América Latina: el rol del Banco Interamericano de Desarrollo. 2002. Disponível em: http://www.sistemasjudiciales.org/content/jud/archivos/notaarchivo/467.pdf. Acesso em: 10 abr. 2017.

HARDT, Michel; NEGRI, Antonio. Imperio. 8. ed. Rio de Janeiro: Record, 2006.

KING, Desmond S. O Estado e as estruturas sociais de bem-estar em democracias industriais avançadas. Novos Estudos Cebrap, São Paulo, n. 22, out. 1988.

MARTINS, Carlos Eduardo. A conjuntura contemporânea e o sistema mundial: os desafios da América Latina no século XXI. In: MARTINS, Paulo Emílio Matos; PIERANTI, Octavio Penna (org.). Estado e gestão pública: visões do Brasil contemporâneo. 2. ed. Rio de Janeiro: Editora FGV, 2007.

MEDINA, José Miguel Garcia; WAMBIER, Teresa Arruda Alvim. Recursos e ações autônomas de impugnação. 3. ed. São Paulo: Revista dos Tribunais, 2013. 
MENDES, Gilmar Ferreira; BRANCO, Paulo Gustavo Gonet. Curso de Direito Constitucional. 12. ed. rev. e atual. São Paulo: Saraiva, 2017.

NOHARA, Irene Patrícia. Reforma administrativa e burocracia: impacto da eficiência na configuração do direito administrativo brasileiro. São Paulo: Atlas, 2012.

POCHMANN, Márcio. Política social na periferia do capitalismo: a situação recente no Brasil. Ciências e Saúde Coletiva, v. 12, n. 6, p. 1.477-1.489, 2007.

PORTELLA FILHO, Petrônio. O ajustamento na América Latina: crítica ao modelo de Washington. Lua Nova, n. 32, São Paulo, p. 101-132, abr. 1994.

RAMOS, Edith Maria Barbosa; DINIZ, Isadora Moraes. O Banco Mundial e a Reforma do Judiciário na América Latina. In: COUTO, Mônica Bonetti; ESPINDOLA, Angela Araújo da Silveira; SILVA, Maria dos Remédios Fontes (org.). (Re)pensando o Direito: desafios para a construção de novos paradigmas. 23. ed. Florianópolis: Conpedi, 2014. Disponível em: http://www.publicadireito.com.br/artigos/?cod=4974a9fe76a5b447. Acesso em: 10 maio 2017.

RIBEIRO, Hélcio. Constituição, participação e políticas públicas. In: SMANIO, Gianpaolo Poggio; BERTOLINI, Patrícia Tuma Martins (org.). O Direito e as políticas públicas no Brasil. São Paulo: Atlas, 2013.

RIEGO RAMÍREZ, Cristián. Informe comparativo: proyecto de seguimiento de los procesos de reforma judicial en América Latina. 2004. Disponível em: https://revistas.juridicas.unam.mx/index.php/reforma-judicial/article/view/8657/10687. Acesso em: 14 abr. 2017.

RIEGO RAMíREZ, Cristián. Seguimiento de los Procesos de Reforma Judicial en América Latina: segundo informe comparativo. 2003. Disponível em: http://www.sistemasjudiciales.org/content/jud/archivos/notaarchivo/552.pdf. Acesso em: 14 abr. 2017.

ROWAT, Malcom et al. Judicial reform in Latin America and Caribbean: proceedings of a World Bank conference. World Bank Technical Paper, Washington D.C., n. 280, June, 1995.

SILVA, José Afonso da. Curso de Direito Constitucional Positivo. 39. ed. São Paulo: Malheiros, 2016.

SOUSA, Monica Teresa Costa. Direito e desenvolvimento: uma abordagem a partir das perspectivas de liberdade e capacitação. 1. ed. Curitiba: Juruá, 2011.

TOMIO, Fabrício Ricardo de Limas; ROBL FILHO, Ilton Norberto. Accountability e independência judiciais: uma análise da competência do Conselho Nacional de Justiça (CNJ). Revista de Sociologia e Política, v. 21, n. 45, p. 29-46, mar. 2013. 